\title{
QUEEN'S
UNIVERSITY
BELFAST
}

\section{Future city visions. The energy transition towards carbon-neutrality: lessons learned from the case of Roeselare, Belgium}

Pulselli, R. M., Broersma, S., Martin, C. L., Keeffe, G., Bastianoni, S., \& van den Dobbelsteen, A. (2021). Future city visions. The energy transition towards carbon-neutrality: lessons learned from the case of Roeselare, Belgium. Renewable and Sustainable Energy Reviews, 137, [110612]. https://doi.org/10.1016/j.rser.2020.110612

\section{Published in:}

Renewable and Sustainable Energy Reviews

\section{Document Version:}

Peer reviewed version

Queen's University Belfast - Research Portal:

Link to publication record in Queen's University Belfast Research Portal

\section{Publisher rights}

Copyright 2020 Elsevier.

This manuscript is distributed under a Creative Commons Attribution-NonCommercial-NoDerivs License

(https://creativecommons.org/licenses/by-nc-nd/4.0/), which permits distribution and reproduction for non-commercial purposes, provided the author and source are cited.

\section{General rights}

Copyright for the publications made accessible via the Queen's University Belfast Research Portal is retained by the author(s) and / or other copyright owners and it is a condition of accessing these publications that users recognise and abide by the legal requirements associated with these rights.

\section{Take down policy}

The Research Portal is Queen's institutional repository that provides access to Queen's research output. Every effort has been made to ensure that content in the Research Portal does not infringe any person's rights, or applicable UK laws. If you discover content in the Research Portal that you believe breaches copyright or violates any law, please contact openaccess@qub.ac.uk. 


\title{
3 Future City Visions - The Energy Transition Towards Carbon-Neutrality - Lessons 4 learned from the case of Roeselare, Belgium
}

\author{
Riccardo Maria Pulselli ${ }^{1}$, Siebe Broersma ${ }^{2}$, Craig Lee Martin ${ }^{3}$, Greg Keeffe ${ }^{4}$, Simone Bastianoni ${ }^{5}$, Andy van den \\ Dobbelsteen $^{2}$ \\ ${ }^{1}$ University of Siena (IT). Santa Chiara Lab. \\ ${ }^{2}$ Delft University of Technology (NL). Faculty of Architecture and the Built Environment. \\ ${ }^{3}$ University of Central Lancashire (UK). School of Art, Design and Fashion. \\ ${ }^{4}$ Queen's University of Belfast (UK). School of Natural and Built Environment. \\ ${ }^{5}$ University of Siena (IT). Ecodynamics Group. Department of Physical Sciences, Earth and Environment.
}

Abstract

As climate change develops, with most of the world population living in urban areas, decarbonisation of cities is among the greatest challenges of the coming decades. In the framework of the EU City-zen project, a number of socalled Roadshows has been organised in ten cities within and outside Europe in order to plan and kick-off their transition towards an energy- and climate-neutral economy. During the Roadshows, a group of experts is engaged to perform co-working activities and participative labs involving local stakeholders. These activities support cities in identifying their own decarbonisation pathways, mainly by combining three mutual processes, i.e. energy design, urban design and carbon accounting. The latter, in particular, has been used to quantify the greenhouse gas emissions of cities and neighbourhoods and to estimate the mitigation effect of a combination of measures towards the desirable condition of carbon neutrality. This exploratory and proactive design process has been successfully demonstrated through intensive workshops and can be potentially replicated in other cities. This paper provides a schematic overview of the main results achieved in the Belgian town of Roeselare, but more significantly it describes the techniques needed to make that cooperative process understandable, impactful and implementable. It is likely that 2050 European goals will drastically change urban environments and socio-economic dynamics in cities, due to the fragmentation of energy sources. Hence, from this standpoint there is a vital need for integrated technologies and infrastructures, a circular economy and community-based processes such as food production, sharing of facilities and valorisation of ecosystem services. The City-zen Roeselare Roadshow brought over 300 stakeholders into the process of re-imagining and visualising their 2050 future city with these solutions. Stakeholders, with no particular expertise in carbon accounting or sustainability, would now have the capability of understanding and applying these solutions in a combined effort to meet the zero-carbon challenge. The approach is generally replicable elsewhere being highly visual, impactful, transferable, and multi-stakeholder friendly. Given that data are made locally available, the combination of this general approach, site-specific assessments and the involvement of both experts and local stakeholders (i.e. policy makers, citizens, etc,) allow the transition to start by referring to any real city or neighbourhood. 


\section{Introduction}

Today $55 \%$ of the world's population lives in urban areas, a proportion that is expected to increase to $68 \%$ by 2050 (UN 2018); moreover, as the world population is expected to increase by a further $30 \%$, the associated change in climate will be significantly affecting ecosystems and global land use. In Europe, the level of demographic urbanization is approximating 74\%. Accordingly, the European Commission's long-term strategy (EC 2018) interprets cities as ideal laboratories for transformative and sustainable solutions. City refurbishment and better spatial planning, including that of green spaces, can be major drivers to pursue the aim of net-zero greenhouse gas (hereafter, GHG) emissions by 2050 , likely through a socially fair transition in a cost-efficient manner.

The EC strategy $(E C, 2018)$ points the way forward to a carbon-neutral economy by referring to a set of joint actions:

- improving energy efficiency in buildings, which today are responsible for $40 \%$ of energy consumption;

- maximising the deployment of renewables and the use of electricity to fully decarbonise Europe's energy supply;

- embracing clean, safe and connected mobility, currently responsible for around a quarter of the GHG emissions in the EU;

- fostering circular economy as a key enabler to reduce GHG emissions, starting from reducing the input of materials through reuse and recycling, and significantly modernising or replacing existing installations;

- developing an adequate and smart infrastructure ensuring optimal interconnection, especially to support the major developments framing the energy transmission and distribution landscape of tomorrow;

- reaping the full benefits of bio-economy enhancing capacity of agriculture and forestry to provide sufficient food, feed, and fibres as well as to support the energy sector and various industrial and construction sectors.

- enforcing carbon sinks, as important as reducing emissions, by maintaining and further increasing the natural sinks of forests, soils, and agricultural lands and coastal wetlands;

- tackling remaining $\mathrm{CO}_{2}$ emissions with carbon capture and storage previously seen as a major decarbonisation option for the power sector and energy-intensive industries.

Urban areas will be the first centres of innovation regarding most of the actions mentioned in the EC strategy. The strategy also states that, combined with the transition to carbon-free technologies, behavioural changes by individuals and companies must underpin any evolution: "making the transformation towards a net-zero GHG economy is not just about technologies and jobs, it is about people and their daily lives, about the way Europeans work, transport themselves and live together" (EC 2018).

Before the delivery of the last EC directives for climate action, an articulated framework to kick-off decarbonisation of European city neighbourhoods has been implemented in the work-plan of the EU City-zen project (City-Zen 20152019), much in advance and fully in line with the EC strategy actions. It has been tested since 2015 in a series of events organised throughout cities in Europe and outside. The so-called 'City-zen Roadshows' have been conceived as itinerant laboratories involving a group of international experts together with local stakeholders. The Roadshow aims to point the way towards energy and carbon neutrality of the hosting cities and their neighbourhoods. Combining global expertise of specialists with local stakeholder knowledge of specific contexts and lifestyle, the Roadshows perform a participative design process to figure out future scenarios and finally co-create a sustainable "city vision" resulting from a progressive and reliable transition plan. The scope of each Roadshow is to imagine how our cities would appear, operate and contribute to healthier lifestyles by 2050, imaging their energy transition accomplished, and use these forecasts to inspire local stakeholders, unlock stasis and kick-off the decarbonisation way-out.

The City-zen Roadshow series has been hosted in Amsterdam (NL), Belfast (UK), Izmir (Turkey), Dubrovnik (HR), Menorca (ES), Sevilla (ES), Roeselare (BE), Preston (UK), Nicosia (CY), and Amersfoort (NL). Dobbelsteen et al. (2018a) presented outcomes from the Roadshow in Dubrovnik focussing on the Gruž neighbourhood. The decarbonisation scenario presented combines technologies for renewable energy generation, such as PV panels and wind turbines, with innovative solutions of circular economy concerning sewage treatment from cruise ships and algae farms to generate biogas, biofuel and other materials (e.g. fish-feed for aquaculture). Moreover, the transport system from the harbour to the old town of Dubrovnik was reorganised to respond to significantly high flows of tourists and cruise ship passengers. Pulselli et al. (2018b) showed results from the Roadshow in Sevilla, mainly referring to a district heating/cooling network fed by heat pumps connected to underground aquifers as renewable heat/cold source in the Tiro de Linea neighbourhood. Electrification through PV panels on roofs and canopies and greenery systems on facades were advised, also to mitigate the intense urban heat island (UHI) effect. Marchi et al. (2018) presented a similar approach for the energy transition of the historical centre of Siena, a UNESCO heritage site, through full electrification and the provision of a "solar belt" on available flat roofs of productive and commercial districts around 
the city centre. Marchi et al. (2017) also assessed the effect of green valleys within the historic centre in terms of carbon uptake.

Regarding the practice of participative design and visioning of future scenarios, Krzywoszynska et al. (2016) presented outcomes from a participatory process developed in Stocksbridge (UK) based on models and visualizations, using images, maps and physical representations to enable a bottom-up engagement of citizens, bringing together scientific knowledge and local perspectives. The process aimed at creating models of desired future for energy systems, matching electricity generators and energy storage with electricity demand, and demonstrated how technological and social innovation may result in greater diversity and appropriateness of solutions, depending on local contexts. Acero López et al. (2019) experienced a design process based on a Soft Systems Methodology that engages the participants to figure out innovative solutions in the specific field of water management and saving. The active involvement of the community in the design process, including prototyping, allows to give visibility to the initiatives and rise awareness about the use of natural resources. Nevens et al. (2013) show a framework for Urban Transition Labs based on a sequence of steps. After a preliminary analysis, a participative process of imaginary scenario building (envisioning) is employed to create inspiring visions, based on shared principles of sustainable development. Starting from these visions, different strategic transition pathways, including the experimentation of alternative ways of living, to realise the desired future situation are outlined. To this aim, monitoring instruments for assessing potential effects of the actions planned are used, not just to 'measure' but rather to trigger action, to enhance system change in a desired direction. More in general, a comprehensive overview on quality criteria for sustainability visioning practices, as a method for depicting how a desirable future might look and for planning urban transformations, is provided by Wiek \& Iwaniec (2014). The authors highlight how creating models of desired futures, made of images, maps and physical representations, is part of the visioning process; rather than being just informative as common scenarios, visions must be visionary (including aspirational surprise), systemic, coherent, plausible, tangible, relevant (focus on people, their roles, and responsibilities), nuanced, motivational and shared.

This paper makes a further step in the direction of determining consistent procedures to quickly support decisions and efficiently address participative processes to plan action for climate. As main reference for the evaluation and assessment performed in this study, Pulselli et al. (2018a) provided a comprehensive carbon accounting framework as implemented and tested through City-zen Roadshows; in order to provide a robust benchmark, it refers to an average European household and neighbourhood based on Eurostat data. The experience in Roeselare here presented is a practical demonstration of this framework, first applied to assess the carbon emission of the targeted neighbourhood and then to determine the decarbonisation strategy. Moreover, the co-creative and socially impactful methodology has been described by Martin et al. (2017) to be replicable in any context and for demographically diverse audiences whose specialisms may, or may not be sustainability based.

The paper shows outcomes from one of the most successful City-zen Roadshows hosted in Roeselare (Belgium) and demonstrates how creative inputs from a multidisciplinary assembly of experts and local stakeholders can drive cities though the process of becoming energy and carbon neutral. This research does not cover all aspects of energy and urban planning or carbon accounting but rather provides a partial but operative tool to inform processes of instant planning, meaning with "instant" that the proposed framework allows experts to interact, collect information and discuss with local stakeholders, accordingly elaborate plans and assessments and finally communicate results to a wide audience of non specialists, within 5 days of intensive workshop. More complete models exist that can provide exact and exhaustive outcomes, for example on Carbon Accounting of cities or regions (Marchi et al. 2012; Bastianoni et al. 2014), but the experience made in Roeselare has a crucial time factor. The present paper shows a combination of practices that can be replicated and implemented in any city or neighbourhood in a few days to deliver an amount of information, data and graphical issues, rising awareness on sustainable assets, giving visibility to longings and ambition of citizens and filling them with enthusiasm to start a consistent transition towards sustainability. The Cityzen Roadshow is a disruptive kick-off that fosters experts, policy makers, entrepreneurs and citizens to cooperate and finally look at one possible future to pursue and share. How does the 2050 Roeselare (or any other city or neighbourhood) look like? What is the most desirable future for the city? Where should we start from and proceed to achieve the desired results?

\section{Materials and methods}

This section is dedicated to the presentation of case studies and methods that are built on the interaction with local stakeholders to collect data from different sources, identify potentials based on surveys and interviews and make observations through open discussions in round tables. The participative process commits local stakeholders since the beginning to observe and refer on specific issues suggested by experts within their own neighbourhood. Driven by 
experts that give a direction and take the story at their own pace, assuring a certain methodological rigour, information and inputs from people attending the workshop constitute the materials for the next elaborations.

\subsection{The City-zen Roadshow method}

The scope of City-zen Roadshows is to engage city stakeholders with innovative design and technological solutions and facilitate the development of a city roadmap for energy transition and decarbonisation. This aim is met through multidisciplinary group co-working and interactive sessions for knowledge transfer and capacity building, during which a team of international experts, involved as City-zen partners, works closely with people from the hosting city - policy makers, energy planners, practitioners, entrepreneurs, researchers, students and of course, the citizens themselves no matter what age or background.

11 Roadshows are conceived to be implemented in just a few working days, including data collection and elaboration. Activities and events taking place over the five-day programme include onsite investigations, Energy Potential Mapping, creative design workshops relating to social, energy and carbon challenges. Before and during Roadshows, the characteristics of the hosting city/neighbourhood are systematically analysed, leading to good insight into the current challenges and potentials of the city. In close collaboration with local stakeholders, the team of experts investigates the use of energy and emission of GHG, in total numbers and per household, and develops a proposal for interventions that are coherently informed by available hard data from the city and validated by energy and carbon calculations. Designs, calculations and proposed embedment in governance leads to a "City Vision" that is presented to city audience and key decision makers on the final morning.

The extemporary nature of Roadshows, as intensive cooperative sessions with a strict timeline, in certain cases requires assumptions and approximations, but nevertheless provides reliable outcomes. Considering the short term of political mandates and the instability of social-economic-legal variables in our changing world, timely and effective decision support systems are critical.

The Roadshow approach concerns three mutual processes that are complementary implemented, i.e. energy design, urban design, carbon accounting. Energy design is mostly based on the City-zen urban energy transition methodology (Dobbelsteen et al. 2018b; Dobbelsteen et al. 2019). References for the urban design process are Campbell (2018) and Keeffe (2014). The city of Roeselare, with a populace of 61,657 inhabitants (2017) has been taken as a test bed.

\subsection{Carbon Accounting}

The carbon accounting framework refers to a typical GHG emissions inventory, focussing on a limited set of items. These include energy consumption for households and private cars, water use and domestic waste management thus representing a portion, and not the totality, of GHG emitted by the citizens. Several studies concerning the Carbon Footprint of cities have highlighted the importance of other factors not included in this assessment, for example the indirect emissions released in the global supply chain during the production of final goods and services (Minx et al. 2013; Lenzen and Peters 2010; Suh et al. 2004; Chen et al. 2016; Fry et al. 2018) or those associated to trade (import and export of goods) through a consumption-based approach (Lenzen 2001; Wiedmann et al. 2010, Caro et al. 2014, 2017). Nevertheless, the GHG inventory performed here, far from being exhaustive, aims at monitoring energy, waste and water flows as crucial information to drive design practices.

The GHG inventory is made in compliance with the Global Protocol for Community-Scale GHG Emissions Inventories (GPC) (GHG Protocol, 2014); in particular, the GHG emissions monitored occur within the city and refer to the GPC scope 1. Nevertheless, the Emission Factors selected include indirect emissions generated by lifecycle processes of electricity generation (by referring to the national grid mix), fuel production, water and waste management; the accounting framework adopted therefore refers to the GPC scope 2 concerning input flows crossing throughout city boundaries. Kennedy and Sgouridis (2011) define this category as external emissions directly caused by core municipal activities. Emissions occurring outside (scope 3 ) are not included in the observation. The classification of urban emissions into three scopes, allows for the definition of carbon strategies and aims to enforce technical constraints on activities that fall under the jurisdiction of a municipal authority, while allowing for flexibility in balancing emissions for activities outside the city boundaries; accordingly, the Carbon Neutral label mentioned in this study implies that any and all emissions for which the city is responsible under Scopes 1 and 2 are fully eliminated or balanced through internal or external sequestration (Kennedy and Sgouridis 2011). of the city and, afterwards, to ex-ante estimate the effects of GHG emission mitigation measures. 
Statistical data refers to the Municipality of Roeselare. Datasets have been provided directly by the "climate group" of the Municipality mainly referring to the West-Vlaanderen Province (2015) online database and the statistics on energy use in Belgium (Febeg 2015). The energy demand for industry has been partially considered (estimated 100 $\mathrm{GWh} /$ year) because the energy supply of industrial production has been omitted (this would need very specific interventions for optimisation and impact mitigation such as that concerning a product and its lifecycle processes). The Carbon Accounting procedure systematically follows the framework presented by Pulselli et al. (2018a), including values of Emission Factors (EF). In particular, the EF for electricity has been assessed based on the electricity grid mix of Belgium (i.e. $0.181 \mathrm{~kg} \mathrm{CO} 2 \mathrm{eq} / \mathrm{kWh}$, given: $29 \%$ thermoelectricity powered by natural gas; $51.7 \%$ nuclear; $17.9 \%$ renewables; $1.4 \%$ net import). The impact of energy use in different sectors has been assessed based on the use of different fuels. Both electricity and fuel mix per sector are shown in Table 2.1.1, together with the EF used per each fuel (IPCC 2006) and the calculation of EF of fuel mix per each sector, based on current uses (Data sources: WestVlaanderen Province 2015 and Febeg 2015).

Results from the Carbon Accounting process are shown in Table 2.1.2 considering different emission sources. The carbon accounting follows the framework provided by Pulselli et al. (2018a), including the Emission Factors per emission source (IPCC 2006) and the assessed EF per fuel mix. These also include impacts of waste and water management systems. In particular, the impact of domestic waste treatment depends on the waste management system that currently exists in the area (i.e. $0.256 \mathrm{~kg} \mathrm{CO} 2 \mathrm{eq} / \mathrm{kg}$, given: $29 \%$ waste to energy; $21 \%$ organic; $4 \%$ landfill; $46 \%$ recycling). Electricity has been aggregated considering the demand of the different sectors (West-Vlaanderen Province 2015 and Febeg 2015). Only electricity for public lighting is shown separately in the table. The carbon emission of Roeselare has resulted in 351,842 $\mathrm{t} \mathrm{CO} 2 \mathrm{eq}$ on annual basis (2017).

In order to drive the transition process, with special attention for the housing sector, a typical household in Roeselare has been profiled by scaling down municipal data $(26,349$ households have been assumed within the municipality, given 2.34 inhabitants per household and 61,657 inhabitants - Our assessment from: Roeselare in cijfers 2017). The GHG emission of a household in Roeselare is therefore 6.75 tonne $\mathrm{CO}_{2}$ eq/year.

The Carbon Accounting procedure has been incrementally developed to perform in the intensive and short period of a Roadshow. Compared to a standard GHG inventory, it allows for assumptions and approximations, nevertheless outcomes are coherent and have a required level of detail. From the scale of the household to that of the city, they are used to evaluate strategies of energy transition and drive choices of both energy and urban designers.

\subsection{Energy Potential Mapping}

The basic approach of Energy Potential Mapping concerns the definition of current energy demand and energy potentials in the first step, to calculate feasible scenarios in the next step (Broersma et al. 2013). This includes interventions from the scale of single households to that of building blocks and streets, up to the neighbourhood and the whole city.

Statistical data of the current energy use in Roeselare have been analysed and compared to realistic energy potentials from renewable sources in the city to plan for the most realistic energy strategy with the goal of becoming carbon neutral. Electricity demand has been calculated to be almost $500 \mathrm{GWh} /$ year, whereas the potentials are estimated to be almost $780 \mathrm{GWh}$ /year. For proper estimations, the physical context, local climatic conditions and technical limitations of electricity production have been studied, e.g. available roof surfaces and non-roof surfaces for energy 
production, annual solar radiation, average wind speed, efficiencies of solar panels and wind turbines and the availability of waste (Figure 2.2.1).

For the installation of photovoltaic (PV) panels 235 hectares of roof are available (around $45 \%$ of the built environment is residential representing around 26,250 units - Source: Roeselare in cijfers 2017; with an estimated average of $100 \mathrm{~m}^{2}$ per residential unit divided by an estimated 2.5 layers implies $40 \mathrm{~m}^{2}$ of roof surface per residential unit and 235 ha for the entire BE of Roeselare), of which $50 \%$ is considered to be suitable for energy production. 80 hectares are estimated (for non-roof PV installation) to be available along roads (along an estimated $160 \mathrm{~km}$ of large roadways and railways, a strip of $5 \mathrm{~m}$ width of panels can be installed) and there is space for 40 large $4 \mathrm{MW}$ wind turbines considering a reasonable distance between turbines (around $450 \mathrm{~m}$ for $160 \mathrm{~m}$ high towers) and, keeping local regulations for installation in mind, minimum distance from buildings (usually around 200-250 m). General criteria for designing wind farms have been systematically discussed by the Landscape Observatory of Cataluniya (OPC 2013). And finally the amount of waste-to-energy power is estimated.

Similarly, the heat demand (around $712 \mathrm{GWh} /$ year) can be supplied by a series of potentials of high-temperature (HT), medium-temperature (MT) and low-temperature (LT) sources with an estimated potential of $4735 \mathrm{GWh} /$ year (Figure 2.2.2). The use of $M T$ and $L T$ sources in existing buildings most often requires energy renovations.

HT sources (above $65^{\circ} \mathrm{C}$ ) include heat from waste incineration, based on the caloric value of the current waste stream of Roeselare (130 GWhth/year), the estimated amount of industrial waste heat (100 GWhth/year) and some of the potential of solar heat from solar collectors mounted on the available roof surface (1480 GWhth/year). In figure 2.2.2 half of this last potential is dotted, to indicate that the potential from energy on roofs is 'shared' with the potential of $\mathrm{PV}(\mathrm{T})$. The estimate of residual heat is prudential and covers a limited range of thermal energy potentials (6\% from industrial processes and $8 \%$ from waste incineration) assuming that some industrial sources in the future might change into MT and LT thanks to renovation and waste incineration be replaced by alternative treatments.

MT $\left(40^{\circ} \mathrm{C}-65^{\circ} \mathrm{C}\right)$ sources include most of the potential of solar heat from solar collectors and residual heat from cooling and some industrial processes (estimated to be $25 \mathrm{GWh}_{\mathrm{th}} /$ year). Heat of this temperature can be stored in closed-loop Borehole Thermal Energy Storage (BTES).

LT (below $40^{\circ} \mathrm{C}$ ) sources are PV-thermal heat, which is heat of around $30-35^{\circ} \mathrm{C}$ from PVT panels, solar panels that produce electricity and heat, and waste heat from greenhouses and buildings themselves, which can be stored in open-source Aquifer Thermal Energy Storage (ATES) systems in the underground.

<FIGURE 2.2.1>

<FIGURE 2.2.2>

\subsection{Urban analysis}

Urban designers drive the co-creative workshop sessions that primarily focus on spatial planning, social connections and design. The urban design team of the Roadshow aims to co-develop with the energy team a series of interventions that not only change the energy performance of the neighbourhood, but embody spatially the new lifestyles engendered in the carbon transition. Here, local context, community, culture and lifestyle influence the design outcomes, essentially starting from a focus on qualitative analyses of the built environment. Despite the high variability of conditions and challenges, the urban planning approach can be synthesized through a schematic sequence of design concepts, consisting in matching a set of identified challenges with a set of potential solutions. This is developed and communicated through producing a meta-language of ideograms. The ideograms themselves were created using a method similar to that described by Lynch (1964), which helped define a series of typologies of extant urban structure and identify sub-organisations based on existing urban morphology. These ideograms help frame a conversation around urban space, lifestyle and technological insertion, which at first is critical of the existing urban structure, and then develops new synergies which are centred around this place-based critique. The ideograms produce a clear and simple layered narrative, which can be easily communicated to stakeholders and which later provides a clear justification for new design trajectories, which will embody the climate transition. Figure 2.3.1 shows a series of 15 ideograms representing the main city-neighbourhood-specific challenges identified in Roeselare: 
Figure 2.3.2 shows the typical layout of peripheral neighbourhoods in Roeselare, in order to better interpret the road network at both the city and neighbourhood scale, the integration of built and natural environment and the flood risk.

- Dispersive neighbourhood: due to car-led urban design, clear orientation and organisation are often missing.

- Low density: the sequence of detached houses in between open green areas (mostly grasslands) contributes to determine a dispersive landscape and avoid efficiency of services such as public transport.

- Low intensity: the lack of specific urban functions in neighbourhoods (such as any aggregating centre with shops, restaurants and bars) and elements of identity is a weakness.

- Empty but full: because of the low density of built volumes, all of the space in the neighbourhood is used, and thus urban spaces do not allow many options for interventions and densification due to unclear and disoriented layouts.

- Small green spaces: despite the presence of a plethora of green areas, these are not specifically designed and do not perform ecosystem services that can be expected in urban contexts, including accessibility and use by citizens and proper environmental management.

- No need to visit: there is no evidence of elements that can represent a form of specialisation or identity of neighbourhoods, except for the city centre.

- Car-orientated: as in most of contemporary cities, peripheral areas leave much space to private car use by road networks and parking areas often neglecting or compromising human relations, pedestrian facilities and any chance for neighbourhood communities to emerge and act accordingly.

- Over-engineered roads: both the city scale and neighbourhood road networks are very much car-orientated, with little access for walking or cycling and represent consistent barriers to any connection and relationship.

- No natural environment: green areas are often left to an essential management with no care of vegetation, ecosystems and ecological corridors and do not perform any ecosystem service.

- Isolated from natural environment: physical barriers and fences oppose to the connection between the built and the natural environment beyond the city boundary with minimum interaction.

- Over-engineered waterways: problems of flooding are frequently encountered due to an unwise management of waterways and there is a lack of naturally-based controls and drainage systems to increase resilience.

<FIGURE 2.3.2>

Both the figures are examples of concepts emerged trough the observation made by stakeholders under the guide of experts. Different issues would emerge in different target neighbourhood but this simple and intuitive procedure can be easily replicated elsewhere through the engagement of participants with no specific technical competences.

\subsection{Stakeholders engagement}

The Roadshow has many societal benefits and impacts. In Roeselare, one main impact was the large number of stakeholders (300 according to official municipality figures) who participated in both pre-Roadshow design activities and during the 5 day Roadshow itself. This total being rising significantly following the 'Roadshow Revisit', an additional part of the method that facilitates a post-Roadshow discussion on what influence the Roadshow had in 
terms of policy change. An evidence is the study published by Juwet (2019) dealing with a district heating network in Roeselare; the 'heat backbone' is indicated as a new spatial figure carrying sustainable urban development and densification projects elaborated by the author "based on workshop drawings and discussions".

Various types of professionals, townhall representatives and citizens joined the event. Their backgrounds varied from specialised energy expert to interested local non-expert. A wide spectrum of volunteers and governmental local and regional bodies contributed. For example, the energy team from the Municipality of Roeselare, Energie en Duurzaamheid bij Stad Roeselare, worked alongside to volunteer community groups including many residents from the 'Collievijverbeek' neighbourhood, a focus area for the project. Worthy of special mention is the involvement of education and government organisations based outside Roeselare; a factor that demonstrated how the approach and subsequent findings are both specific to one city and its urban typology, but also generally transferable to the wider region, in this case Flanders. Moreover, the engaged stakeholder groups, from key city decision makers to voluntary organisations, allowed for emphasising the diversity of energy/design expertise, focus and location (local and regional) of the Roadshow participants. Among others, main focus areas and most active stakeholders have included: awareness and strengthening the institutional capacities at the regional scale (Flemish Social Policy Organisation; West Flemish Municipalities; VRP Flemish Association for Space \& Planning); education and research into the energy network in Flanders (Vrije Universiteit Brussel); implementation of new cooperative models (Timelab); urban agriculture research \& development concerned with intensive urban farming and job opportunities (Inagro; Huis van de Voeding - House of Food); protection of endangered plant species and nature in Flanders and Roeselare (Natuurpunt - Voluntary Organisation); waste recycling in Roeselare and Flanders (Mirom); replicability in European city neighbourhoods (European Policy Officer DG ENER).

\section{Results}

Outcomes from participative sessions concern a heterogeneous set of issues regarding urban and architectural design, energy and housing, mobility systems, waste and water resource management. As shown above, site-specific analyses include technical observations of buildings, settlements and infrastructures, social behaviours, local economy, environmental and landscape contexts, carbon emission of households, neighbourhoods and the city. Coherently with critical observations and data elaborations, technical and design issues show extant opportunities for energy reduction and reuse, renewable energy potentials, urban infrastructures and services, nature-based systems and ecosystem services, architecture and urban agriculture, technological and other integrated measures for GHG emission mitigation. Any knowledge, concept, suggestion and proposed design is made understandable through graphics, schemes, draws, sketches, 3D models and images and infographics in order to guarantee a clear and effective communication, and to target the largest audience possible. The final outputs of Roadshows include firstly the production of a comprehensive and coherent narrative of urban space and energy use in that place, and then a process and time-based set of interventions, in both the spatial and technical spheres that allow the development of a new narrative of the city, based on a progressive series of planned actions, which have emerged from co-creative working with the original constructive narrative.

\subsection{Energy design}

The energy design strategy concerns an accurate selection of energy systems and technologies that are to be integrated in the urban context. The 2050 objectives of energy neutrality have been determined and specifically structured based on the most suitable solutions that are identified out of the energy potential analysis.

The electricity demand ( $495 \mathrm{GWh}$ /year), is expected to further increase towards 2050 due to electrification of heating systems (by the use of heat pumps) and to the electrification of transportation. Although the urban population is expected to grow (Roeselare has grown quickly with around $10 \%$ in the last 10 years, a relative slower growth for the next 3 decades is assumed), the increase of electricity use caused by this is expected to be compensated by a relative reduction of electricity use from residential, tertiary and industrial sectors (see figure 3.1.3). This final electricity demand can potentially be supplied by different renewable energy sources including 240 hectares of PV modules (around $350 \mathrm{GWhe} / \mathrm{year}$ ), 25 4MW wind turbines (around $200 \mathrm{GWhe} / \mathrm{year}$ ) and the co-generation by waste incineration (20 GWhe/year). The impact of waste incineration remains accounted in the GHG emission of waste that cannot be fully avoided and will be finally compensated. 
The heat demand of the current building stock ( $712 \mathrm{GWh}$ th $/$ ear) is assumed to decrease in time, because significant effects (20\% reduction is assumed here for the full built environment considering that a usual full energy refurbishment saves around $40 \%$ in heat demand. See Tabula WebTool 2018) can be achieved in terms of energy saving (and replacement of poor performing buildings) due to a robust campaign of building retrofitting. New buildings will have a low additional heat demand and are supposed to be almost energy neutral, so they will produce their own demand. The remaining heat demand for the current building stock ( $565 \mathrm{GWh}_{\mathrm{th}} / \mathrm{year}$ ) can potentially be generated by a combination of HT (30\%), MT (25\%) and LT (25\%) sources (assumed that all available HT waste heat, including from biomass, meets $30 \%$ of the demand, for which the use requires no energy refurbishments and is often the most convenient to get a sustainable heating system. The remaining heat demand will equally be met with solar heat, with seasonal storage, at Medium temperature and Low Temperature) and distributed at the urban scale in collective projects by District Heating Networks (DHN) and Mini Heat Grids (MHG) or by individual systems on heat pumps or other devices.

<FIGURE 3.1.2>

The mobility system also calls for major changes. In figure 3.1.3 the proposed scenario for mobility is shown. The left scheme visualizes the scenario of the modal split. The share of car use of the current modal split (based on data from Klimaat+Plan Roeselare) is assumed to be halved by 2050 by measures concerning improved public transport and behavioural changes with a high increase of light mobility systems like cycling and pedestrian kilometres. In the right scheme the scenario of the electrification of the transport is visualized. With a reduction of around $50 \%$ of the car kilometres, and due to better efficiency of over $50 \%$ of electric engines the final energy demand for transport in 2050 is over 4 times less.

<FIGURE 3.1.3>

In a next and successive step, roadmaps can be derived from the energy transition scenarios, that show measures and actions needed in order to get towards the 2050 vision. For the heat transition for example, renewable sources of high, medium and low temperatures are proposed to replace the current gas (and other fuels) to heat buildings. Yet, the current building stock will not always be suitable to be heated with medium or low temperatures. Therefore energy saving measures for buildings (energy retrofitting) will often be required. With knowledge of the energetic performances of the buildings, as we gradually get more and more in European cities (and as also demanded by the EU's Energy Efficiency Directive) expressed in energy performance labels, we can derive these. Assuming, in the case of Roeselare, that buildings with an A-label performance are able to be heated with low-temperature sources and buildings with a B- or C-label can do it with medium temperatures and need renovations for low-temperature sources. A large part of the building stock in Roeselare has poor labels (D, E, F or G) and can only be heated with high temperature sources or need renovations for medium (or low) temperature heating. The amounts and types of energy renovations can now be expressed in typical measures per year for certain time frames (e.g. 500 renovations from G,F,E or D label residential equivalents to a C or B label per year in the period of 2018-2050). Accordingly, the measures for heat production, storage and other types of renovations can be put in the roadmap as shown in figure 3.1.4. Similar roadmaps were composed for the required measures related to high temperature sources as well as for electricity production. This step again tries to unravel the complexity of energy transitions and demonstrates for city councils for example what is needed to achieve their targets. 
The proposed energy strategy for Roeselare is more concretely developed in a next phase through schematic plans such as shown in Figure 3.1.5. It visualises the layout and size of a city-scale DHN and neighbourhood-scale MHGs, with the location of the main heat energy sources. Moreover, it simultaneously shows the spatial distribution of wind farms, including 25 large turbines and the comprehensive area for 2050 of installed PV and solar thermal collectors. A schematic section representing the integration of different infrastructures, from DHN and MHG to PV on roofs or canopies and wind farms, is shown in Figure 3.1.6.

<FIGURE 3.1.5>

<FIGURE 3.1.6>

\subsection{Urban design}

Designers undertake to integrate technological and infrastructural solutions within local physical and social contexts, not only concerning the energy dimension, but also exploring environmental, social and economic issues of urban design. This part of the process aims to demonstrate how sustainable development can potentially bring consistent gains in the quality of life and wellbeing in general. In many aspects, the co-creative session on urban design is most relevant in terms of stakeholders' engagement and brainstorming. Currently, design decisions made during the urban design sessions are not seen by stakeholders to have a direct link to GHG emission mitigation, due to the lag between the design part of the process, and the re-calculation of the carbon emission taking place at a later time. Future Roadshows will address this by assessing the carbon impact in real time as the designs evolve. The role of designers is crucial to make the urban transition socially more acceptable and to explain more clearly through visual representation the benefits and added value of neighbourhoods becoming energy and carbon neutral.

Figure 3.2.1 shows a series of 10 ideograms representing the solutions for the transition to a sustainable mindset in Roeselare:

- Star-city: connection between peripheral neighbourhoods and the city centre must be improved especially concerning sustainable mobility (e.g. walking and cycling roads) and a deeper penetration of urban facilities inside the neighbourhoods, thus extending the offer of accessible urban spaces and contexts, with different environments and services. In this regard, Figure 3.2.2 specifically focuses on Roeselare and the extension of functions from the centre to the neighbourhoods.

- New green ring: the extension of urban green spaces and the enhancement of ecosystem services is also a desirable issue. This is expected to reconnect natural systems in both the radial and circular directions enforcing the green network of walking and cycling roads as well as ecological corridors.

- Blurred boundaries: the removal of physical and visual barriers through design, including over-engineered roadways and fences, would potentially avoid disconnections and fragmentation and increase permeability among neighbourhoods, maximising opportunities of exchange and cross-fertilisation.

- City unpacking: improved connectivity and accessibility will also contribute to increase attractiveness of different neighbourhoods by enhancing urban services and facilities, identifying specialisations and discovering peculiarities in each urban area, e.g. small businesses, sport facilities, thematic communities, circular economy initiatives or entrepreneurships, periodical events such as weekly markets and yard-sales.

- Neighbourhood connectivity: coherently with the city unpacking, people mobility from place to place throughout peripheral areas will make sense, especially when neighbourhoods improve their attractiveness for specific peculiarities, services or natural environment.

- Shared surface: public places, including roads and green areas, can host community level activities, from renewable energy generation to sport facilities, car and bike sharing, urban gardening and agriculture. Direct engagement of local communities is a desirable issue of urban design considering that most of current urban layouts do not facilitate this and often avoid the emergence of shared initiatives among people and stakeholders.

- Productive landscapes: short supply chain for food provides different benefits including direct engagement of citizens, provision of fresh, healthy and low-carbon food products, emergence of micro-economies for example through local vegetable markets, improved attractiveness for external visitors. Besides food production, other 
The contribution of the Urban Design process in terms of GHG mitigation (see section 3.3) can be directly estimated by referring to passive systems of energy saving, such as by decreasing the UHIE through NBS, or by designing infrastructures for sustainable mobility (e.g. cycling roads), but more often, it supports the implementation of renewable energy systems and other solutions based on the energy potentials analyses. In particular, the role of urban design is crucial to combine solutions, concerning both the technological and the social spheres, that must be integrated in the urban environment, moving from the individual to the community scale. It allows for engaging citizens and emphasizing their role as members of the community, called to support private-public initiatives as well as to change their behaviours and lifestyles.

\subsection{Carbon accounting}

Out of the energy design and urban design sessions, the transition plan for Roeselare has finally identified a sequence of 14 measures that constitutes a potential scenario for carbon neutrality by 2050. Planned actions have been hypothesised based on energy potentials and the urban context, aiming at pursuing the objectives set in 3.1. Table 3.3.1 shows the estimated size of interventions and their effects in terms of GHG emission mitigation.

<TABLE 3.3.1>

The GHG emission of Roeselare is 351,842 tonne $\mathrm{CO}_{2}$-eq per year ( 0 in the table) depending on different sources, including a total demand of $495 \mathrm{GWh} /$ year electricity, $712 \mathrm{GWh} /$ year from a fuel mix for space and water heating, 290 $\mathrm{GWh} /$ year for mobility, 28,000 tonnes of waste/year treated and 2.5 million $\mathrm{m}^{3}$ of water used/year. This marks the starting-point of any transformation process forward.

Next, the different mitigation measures are assessed on their single contribution to the reduction of the GHG emission, whereas in reality, the different measures will all contribute gradually over time towards the final vision for 2050.

Consistent reduction of energy demand can be achieved by building retrofitting and improved insulation (Qian and Lee, 2014). Energy savings (1) have been hypothesised as follows: $-15 \%$ electricity and $-25 \%$ fuel demand for housing; $15 \%$ electricity and $-20 \%$ fuel in tertiary; $-10 \%$ electricity and $-10 \%$ fuel in industry; $-10 \%$ electricity and $-20 \%$ fuel in farms; -50\% electricity demand for public lighting through light replacement with LED lamps (King \& Perry 2017). This action brings the GHG emission down by $14 \%$.

Together with potential energy savings, a certain growth $(G)$ of population and energy demand has been forecasted 
by 2050 due to both population increase and economic growth: $25 \%, 10 \%$ and $20 \%$ electricity for housing, tertiary and industry, respectively; $10 \%$ and $5 \%$ fuel demand for private and public transport, respectively; $10 \%$ increase of domestic waste and water use. The expected increase of the GHG emission in Roeselare is $6 \%$.

The heating supply can be achieved by a smart combination of HT, MT and LT systems. In particular, HT systems would refer to an urban DHN supplied by a combination of different sources; the hypothesised scenario includes $35 \mathrm{GWh}$ supplied by industrial use of biomass (2), $55 \mathrm{GWh}$ by waste incineration (3), $55 \mathrm{GWh}$ by solar collectors connected to a MT underground storage (4), and $55 \mathrm{GWh}$ by industrial heat waste (5). All numbers on energy (in GWh) are from the measures from the schemes in 2050 as presented in figures 3.1.1 - 3.1.3. The avoided use of fuels would correspond to $15 \% \mathrm{GHG}$ reduction. Moreover, a combination of solar collectors with MT storage can potentially supply $165 \mathrm{GWh}$ through MHG in given locations (6) with a corresponding GHG reduction of $12 \%$. Similarly, LT MHG's can combine PVthermal systems installed on roofs of single houses or housing blocks and LT Aquifer Thermal Energy Storages (7).

The electricity demand can also be supplied by local renewable sources. The selected scenario realistically forecasts 12 $\mathrm{GWh}_{\mathrm{e}}$ provided by waste incineration (3), $345 \mathrm{GWh}$ by PV installed both on roofs and other horizontal or vertical surfaces (9), $138 \mathrm{GWh}$ by wind turbines (10). The latter will be further enlarged to $203 \mathrm{GWh}$ (13) to cover the additional demand of next measures.

Sustainable mobility is among the desirable measures to be implemented. The increased use of bicycles and public transport (11) would avoid the use of $125 \mathrm{GWh}$ of fuels for private cars, corresponding to a GHG reduction of $10 \%$. Moreover, a full transition to electric mobility (12) can be forecasted in the long run, providing an avoided use of 194 GWh of fuels with an additional electricity demand of around $64 \mathrm{GWh}$ to be potentially supplied by wind farms (13).

GHG emission mitigation measures also concern waste recycling, with a drastically decrease of landfilled waste, and a consistent reduction of water use by behavioural changes and water harvesting systems for different uses (14).

The combination of designed measures above is supposed to bring the initial GHG emission to a much lower value, i.e. 4810 tonne $\mathrm{CO}_{2}$-eq (just over $1 \%$ of the initial GHG). This residual GHG, that cannot be avoided due to physical rules (it is a form of entropy) and can be compensated by 356 ha of urban forestry (15).

The effects of GHG emission mitigation measured used in Roeselare have been estimated based on general assumptions determined in compliance with the carbon mitigation measures systematically presented in Pulselli et al. 2018a. The sequence of measures above composes one possible scenario, among others, for a future energy and carbon neutral Roeselare.

\section{Discussion}

Carbon accounting, combined with energy design and urban design, is a crucial aspect of the framework presented. Solutions for energy transition and climate-neutral cities can be designed considering different scales for interventions, both spatial (from the single household to the neighbourhood, to the city scale) and temporal (short-, medium-, or long-term implementation period). Moreover, they can include different strategies, referring to new technologies in buildings and infrastructures in the built environment, or even to behavioural changes, through specific campaigns for raising awareness (the Roadshow itself is part of these), involving citizens and communities. In this regard, communication plays a crucial and relevant role. In order to make the challenges, design steps and Roadshow proposals more easily understandable by stakeholders whose background is likely not one from environmental design or analysis, the visualisation of a city's GHG emission, and indeed new technological and spatial infrastructures can be an effective tool to motivate and foster climate action.

42 Roeselare's GHG emission has been represented graphically with an area of forestland needed to compensate GHG emission through carbon uptake, as demonstrated by Pulselli et al. (2018). Figure $4.1 \mathrm{impactfully} \mathrm{shows} \mathrm{that} \mathrm{the}$ virtual forest of Roeselare (26,062 hectares) is five times the area of the city itself $(5,979$ hectares). This schematic representation comprised on $1 \mathrm{~km}^{2}$ squares of forest, empathises the influence of different emission sources through colours, allowing local stakeholders to become conscious of the initial challenge to be faced.

Similarly, the impact of any single household has been spatially visualised; the emission of 6.7 tonne $\mathrm{CO}_{2}$ eq/year per household in Roeselare corresponds to 0.5 hectares forest, the size of a football pitch. Compared to the European average, i.e. 6.9 tonne $\mathrm{CO}_{2}$ eq/year per household (Pulselli et al. 2018), citizens in Roeselare provide lower impacts but this modest result is mostly due to the low emission of the national electricity mix ( $52 \%$ nuclear, $18 \%$ renewables), not 
The schematic representation of proposed or required energy measures for energy and carbon neutrality over time, their visualisation in city maps and schematic sections and potential 3D visualisation of solutions at the building scale also contribute to the comprehension of what a full energy transition implies.

<FIGURE 4.1>

The starting-point in Roeselare, as in most of EU cities, is very challenging and the goal of decarbonisation is ambitious enough. Nevertheless, the sequence of solutions selected in the 2050 decarbonisation scenario above clearly shows that paths have been set out. In order to be more effective in engaging local stakeholders, the GHG emission mitigation effect of each measure has been represented in terms of avoided emission and corresponding forestland. In particular, each of the actions has been represented in the sequence in Figure 4.2, including the current state (0), the expected growth by 2050 (G) and the residual emission (14) that requires final compensation by urban forestry. During a Roadshow this sequence is shown dynamically and, in order to highlight any step in the series, the yellow hero of the Pacman game is represented in the figures, crunching forest squares, to animate the sequence. Rather than dumbing down challenges, the Pacman contributes to attract the attention and let every stakeholder in the audience start their own personal transition process.

Most of the GHG emission mitigation is clearly related to solutions planned through energy design. The effects of both behavioural and technological solutions have been accounted and contribute to the carbon crunching. By visually depicting a positive rewarding action, similar in behaviour to that of a world known arcade character who eats (or 'crunches') objects to gain health, has been an extremely powerful tool in engaging non-expert and expert communities across Europe and beyond. Not only has the use of this character and its animated action helped explain how forestland can theoretically sequester and visual 'see' the carbon cause and effect of our lifestyles in current and future scenarios, it does so instantly at all scales from the individual to the infrastructural, through to the regional, and in the cases of Cyprus (2019) and Menorca (2016), the island scale. As described in the UN Sustainability Development Report (2019) projects should take on the challenge of developing tools and methods for multi-stakeholder engagement. This forestland carbon 'crunching' character is a highly disarming, non-patronizing feature that should not be underestimated having demonstrated immediate knowledge transfer impact in nine cities, capturing the imagination of many who have crossed both sides of the expert and non-expert divide.

The urban design approach is indirectly considered in numerical terms; it operates mostly on a qualitative sphere. The design of urban spaces, organisations and communities is nevertheless essential for the success of the initiative, particularly stressing the concept that more sustainable cities do not foresee any loss but, on the contrary, they would possibly imply gains for citizens from any social class, by improving welfare, investments and business opportunities. Urban design contributes to highlight social, economic and environmental benefits of the transition to carbon-neutral cities that end to look more desirable and appealing than they currently are. Figure 4.3 shows two of the street views released at the end of the Roadshow in Roeselare, particularly concerning urban agriculture and greenhouses integration in residential architecture. It strengthens opportunities to start a consistent climate action and kick off Roeselare's decarbonisation.

<FIGURE 4.3>

From the outset in 2015 all Roadshow activities have been continually adapted to gain broad public support and buy- 
in for a transition to carbon neutral cities. Factors that can now be officially referred to in the United Nations Sustainable Development Report (Sachs et al. 2019), a document mirroring the Roadshows position that transition cannot be the sole responsibility of government. As a consequence, the method is highly replicable and multistakeholder friendly, with a generalised framework allowing carbon comparisons between cities to be described easily to non-expert stakeholders. This giving trust in the calculations, but also contextualizing the challenge.

6 Though the start and the end (dataset and outcomes) are city specific, the journey is universal, that is the key. Roadshow recognition that stakeholders are expert in the way they live now, and how they want to live in the future, has demonstrated that sustainability is not the role of professionals within the European community and outside, the Roadshow having also taken place in Izmir, Turkey (2015). Stakeholders have varying interests and availabilities, they are unpaid volunteers; involving them meaningfully in complex design processes, and in often heavy technological and carbon scenarios, is the greatest challenge that urban sustainability faces. The success of the Roadshow lays in the unique way it can operate successfully within varying climates, cultures, languages, economies, transport modalities, urban topographies and political circumstances. All Roadshow elements being highly visual, impactful, transferable, replicable, compact, creative, amenable, entertaining and fun. Solutions for zero carbon cities are inevitably radical and the societal benefits are more easily conveyed to stakeholders through live-time, step-by-step, challenge-tosolution, illustrated 'storytelling', graphical 'before' and 'after' imagery that depicts community-familiar streets and landmarks now and in a desirable future.

\section{Conclusion}

City-zen Roadshows are highly successful in that they launch a city and their neighbourhoods into the challenge of decarbonisation. They are intensive co-creative laboratories, built on multidisciplinary competences of global experts interacting with local stakeholders. This paper has presented the procedural steps and outcomes from the Roeselare Roadshow. It makes a step forwards allowing for highlighting various aspects of the Roadshow approach as strengths and opportunities to further expand and improve the Roadshow experience:

- It allows for planning a concrete energy- and carbon-neutral transition strategy by combining and integrating different measures, technologies, infrastructures, ecosystems, communities and lifestyles in the built environment.

- It performs participative design practices to engage citizens and stakeholders, attract investments, launch new initiatives and point the way towards the 2050 goal. Their direct engagement makes design more site-specific and also contributes to increase social acceptance and feasibility of planned strategies.

- It follows an extemporary approach that allows for presenting reliable plans in a few days. This instant process does not pretend to release exhaustive ultimate design but demonstrate benefits of different options and lets local authorities define policies and launch transformation processes within the short term of their political mandate.

- It leverages on competences of global experts and combines three mutual approaches - energy design, urban design and carbon accounting - and finally delivers coherent energy transition plans of hosting cities.

- It contributes to raise awareness on meanings and implications of the energy transition process and decarbonisation on real life through qualitative and quantitative evaluations and their visual representation. For example, energy potential maps, conceptual ideograms and virtual forestland clearly aim at involving the largest audience possible in the design process.

- It delivers consistent and reliable "future city visions" that can be interpreted as a forecast view of cities in 2050, once the goal of carbon neutrality has been achieved.

- It teaches that sustainable development does not deal with losses or resigns but instead with gains in quality of life, welfare, healthiness, resilience and fairness.

The Roadshow framework promotes design practices that can integrate multiple approaches, strategies, spatial and temporal scales, and strengthen the need of climate action based on multidisciplinary knowledge. Additional elements can be added to the framework to improve outcomes and effectiveness of the process. Indeed, the Roadshow concept shows a possible way to combine competences and efforts of different stakeholders and contribute to build capacities and quickly spread out initiatives of energy transition in Europe and worldwide. 
1 The present study has been developed for implementing the activities of the City-zen project that has received

2 funding from the European Union's Seventh Programme for Research and Technological Development and

3 Demonstration under grant agreement No 608702.

4 The Roeselare Roadshow would not have been possible without the commitments and organisational energy of Timo 5 Wyffels, a highly respected member of the Municipality of Roeselare, Energie en Duurzaamheid bij Stad Roeselare. His 6 group of sustainability experts from the Klimaatswitch team gave continuous support during the preparations for the 7 Roadshow. Special mentions must also go to the Mayor of Roeselare, Kris Declercq, whose hospitality, encouragement 8 and enthusiasm brought the Roadshow in meaningful partnership with the city. The day to day organisation and

9 'engine room' of the Roadshow would be powered by the tenacity, amenability and zeal of one young member of the 10 Klimaatswitch team, Janne Ruszkowski. We thank Kris and Janne for helping to make the Roadshow a highly attended 11 and impactful success. The Huis van de Voeding (House of Food) in the city centre of Roeselare was the home of the 12 Roadshow during our co-creative efforts to develop a sustainable City Vision. 


\section{References}

Acero López, A.E., Ramirez Cajiao, M.C., Peralta Mejia, M., Payán Durán, L.F., Espinosa Díaz, E.E. (2019). Participatory Design and Technologies for Sustainable Development: an Approach from Action. Research Syst. Pract. Action Res 32, 167-191.

Bastianoni, S., Marchi, M., Caro, D., Casprini, P., Pulselli, F.M., 2014. The connection between 2006 IPCC GHG inventory methodology and ISO 14064-1 certification standard e a reference point for the environmental policies at sub-national scale. Environ. Sci. Pol. 44, 97-107.

9 Braat, L. C., \& De Groot, R., 2012. The ecosystem services agenda: bridging the worlds of natural science and 10 economics, conservation and development, and public and private policy. Ecosystem services, 1(1), 4-15.

11 Broersma S., Fremouw M.A., Dobbelsteen A. van den, 2013. Energy Potential Mapping: Visualising energy characteristics for the exergetic optimization of the built environment. Entropy 15, 490-506.

Campbell K., 2018. Making Massive Small Change: Building the Urban Society We Want: Ideas, Tools, Tactics. Chelsea Publishing, London (UK).

Caro D., Bastianoni S., Borghesi S., Pulselli F.M., 2014. “On the feasibility of a consumer-based allocation method in national GHG inventories". Ecological Indicators, 36, 640-643.

Caro D., Pulselli F.M., Borghesi S., Bastianoni S., 2017. "Mapping the international flows of GHG emissions within a more feasible consumption-based framework". Journal of Cleaner Production, 147, 142-151.

Chen, G., T. Wiedmann, M. Hadjikakou and H. Rowley (2016) City carbon footprint networks. Energies 9, 602.

Costanza, R., d'Arge, R., De Groot, R., Farber, S., Grasso, M., Hannon, B., Naeem, S., Limburg, Paruelo, J.k., O'Neill, R.V., Raskin, R., Sutton, P., vandenBelt, M., 1997. The value of the world's ecosystem services and natural capital. Nature, 387(6630), 253-260.

De Groot, R. S., Alkemade, R., Braat, L., Hein, L., \& Willemen, L., 2010. Challenges in integrating the concept of ecosystem services and values in landscape planning, management and decision making. Ecological Complexity, 7(3), 260-272.

Dobbelsteen A. van den, Martin C.L., Keeffe G., Pulselli R.M., Vandevyvere H., 2018. From Problems to Potentials -The Urban Energy Transition of Gruž, Dubrovnik. Energies 11, 922; doi:10.3390/en11040922.

Dobbelsteen A. van den, Broersma S., Fremouw M., Blom T., Sturkenboom J., Martin C.L., 2018b. The City-zen Urban Energy Transition Methodology - The Amsterdam Roadmap towards a zero-carbon city. In: Proceedings SASBE2018 112 , Sydney.

Dobbelsteen A. van den, Roggema R., Tillie N., Broersma S., Fremouw M. \& Martin C.L., 2019. Urban Energy Masterplanning - Approaches, Strategies and Methods for the Energy Transition in Cities. In: Droege P. (ed). Urban Energy Transition, from Fossil Fuels to Renewable Power (second edition) (Ch. 5). Elsevier Science Ltd., Oxford (UK).

EC 2018. A Clean Planet for all. A European strategic long-term vision for a prosperous, modern, competitive and climate neutral economy. Communication from the Commission of the European Parliament.

Febeg 2015. Database available at: : https://www.febeg.be/statistieken-elektriciteit

Fry, J., M. Lenzen, Y. Jin, T. Wakiyama, T. Baynes, T. Wiedmann, A. Malik, G. Chen, Y. Wang, A. Geschke and H. Schandl (2018) Assessing carbon footprints of cities under limited information. Journal of Cleaner Production 176, 1254-1270.

GHG Protocol 2014. Global Protocol for Community-scale Greenhouse Gas Emissions Inventories. An Accounting and Reporting Standard for Cities. Report, p. 174.

Keeffe G.P., 2014. Productive Synergies in the city. In: Keeffe \& Roggema (Eds.). Why we need small cows: Design for Urban Agriculture. VHL Press.

Kennedy S, Sgouridis S. (2011). Rigorous classification and carbon accounting principles for low and Zero Carbon Cities Energy Policy 39 5259-5268.

King, J., Perry, C., 2017. Smart Buildings: Using Smart Technology to Save Energy in Existing Buildings. American Council for an Energy-Efficient Economy, p. 46. Report.

Kremer, P., Hamstead, Z., Haase, D., McPhearson, T., Frantzeskaki, N., Andersson, E., Kabisch, N., Larondelle, N., 
Lorance Rall, E., Voigt, A., Baró, F., Bertram, C., Gómez-Baggethun, E., Hansen, R., Kaczorowska, A., Kain, J. H., Kronenberg, J., Langemeyer, J., Pauleit, S., Rehdanz, K., Schewenius, M., van Ham, C., Wurster, D., Elmqvist., T., 2016. Key insights for the future of urban ecosystem services research. Ecology and Society, 21(2): 29.

Krzywoszynska, A., Buckley, A., Birch, H., Watson, M., Chiles, P., Mawyin, J., Holmes, H., Gregson, N. (2016) Coproducing energy futures: impacts of participatory modelling. Building Research \& Information 44:7, 804-815. doi:10.1080/09613218.2016.1211838

IPCC 2006. 2006 IPCC Guidelines for national greenhouse gas inventories. In: Eggleston H.S., Buendia L., Miwa K., Ngara T., Tanabe K. (Eds.). IGES, Japan.

Juwet, G. (2019). Exploring the ambiguous socio-spatial potential of collective heating in Flanders. Planning and design as lever for a sustainable energy transition. European Planning Studies, 1-21.

Lenzen, M., 2001. The importance of goods and services consumption in household greenhouse gas emissions calculators. Ambio 30, 439-442.

Lenzen, M. and G. Peters. 2010. How city dwellers affect their resource hinterland - a spatial impact study of Australian households. Journal of Industrial Ecology 14, 73-90.

Lynch, K., 1964. The Image of the City. MIT Press. ISBN978-0262620017.

Marchi, M., Jørgensen, S.E., Pulselli, F.M., Marchettini, N., Bastianoni, S., 2012. Modelling the carbon cycle of Siena province (Tuscany, central Italy). Ecol. Model. 225, 40-60.

Marchi M., Niccolucci N., Pulselli R.M., Marchettini N., 2018. Environmental policies for GHG emissions reduction and energy transition in the medieval historic centre of Siena (Italy): the role of solar energy. Journal of Cleaner Production $185,829-840$.

Marchi M., Niccolucci N., Pulselli R.M., Marchettini N., 2017. Urban Sustainability: $\mathrm{CO}_{2}$ uptake by green areas in the historic centre of Siena. Int. J. of Design \& Nature and Ecodynamics 12, 4, 407-417.

Martin C.L., Dobbelsteen A. van den, Keeffe, G., 2017. The Societal Impact Methodology - Connecting Citizens, Sustainability Awareness, Technological Interventions \& Co-creative City Visions. International Conference on Passive and Low Energy 03-05 July, PLEA Edinburgh. Vol II, 2791-2798 (ISBN 978-0-9928957-5-4).

Minx, J.C., G. Baiocchi, T. Wiedmann, J. Barrett, F. Creutzig, K. Feng, M. Förster, P.-P. Pichler, H. Weisz and K. Hubacek (2013) Carbon footprints of cities and other human settlements in the UK. Environmental Research Letters 8, 035039.

Observatori del Paisatge 2013. Energia eòlica I paisatge. Orientacions per a una adequada implantacio' a Catalunya.

Generalits de Catalunya. Departament de Territori I Sostenibilitat. Available at:

http://www.catpaisatge.net/fitxers/eeolica_i_paisatge.pdf

Pulselli R.M., Marchi M., Neri E., Marchettini N., Bastianoni S. 2018a. Carbon accounting framework for decarbonisation of European city neighbourhoods. Journal of Cleaner Production 208, 850-868.

Pulselli R.M., Maccanti M., Marrero M., Dobbelsteen A. van den, Martin C., Marchettini M., 2018b. Energy transition for decarbonisation of urban neighbourhoods. A case study in Sevilla. In: Passerini G. (Ed.) Sustainable Development and Planning $X 893-901$.

Qian, X., Lee, S.W., 2014. The design and analysis of energy efficient building envelopes for the commercial buildings by mixed-level factorial design and statistical methods. In: Middle Atlantic American Society of Engineering. Conference.

39 Roeselare in cijfers 2017. Database available at: https://roeselare.incijfers.be/jive/report?ID=wo_evolutie

40 Sachs, J., Schmidt-Traub, G., Kroll, C., Lafortune, G., Fuller, G., 2019. Sustainable Development Report 2019. New York: 41 Bertelsmann Stiftung and Sustainable Development Solutions Network (SDSN).

Suh, S., M. Lenzen, G.J. Treloar, H. Hondo, A. Horvath, G. Huppes, O. Jolliet, U. Klann, W. Krewitt, Y. Moriguchi, J. Munksgaard and G. Norris (2004) System boundary selection in Life-Cycle Inventories. Environmental Science \& Technology 38, 657-664.

Tabula WebTool (2018). Intelligent Energy Europe Program. Database available at: http://webtool.buildingtypology.eu/\#bm

UN 2018. 2018 Revision of World Urbanization Prospects. Population Division of the United Nations Department of 
1 West-Vlaanderen Province 2015. Database available at: http://burgemeestersconvenant.be/2015-provincie-west-

2 vlaanderen-0

3 Wiedmann, T., R. Wood, M. Lenzen, J. Minx, D. Guan and J. Barrett (2010) The carbon footprint of the UK - Results

4 from a Multi-Region Input-Output model. Economic Systems Research 22, 19-42.

5 Wiek, A. \& Iwaniec, D. (2014). Quality criteria for visions and visioning in sustainability science. Sustainability Science, 6 9(4), 497-512. doi:10.1007/s11625-013-0208-6

7

8 
FIGURE CAPTIONS

Figure 2.2.1 - Current electricity demand compared to potentials in the Municipality of Roeselare.

Figure 2.2.2 - Current heat demand compared to potentials in the Municipality of Roeselare.

Figure 2.3.1 - Ideograms of the design hotspots emerged through the participative urban analysis of Roeselare.

Figure 2.3.2 - One representative view and analysis of neighbourhoods in Roeselare.

Figure 3.1.1 - Current electricity demand and 2050 scenario for a carbon neutral municipality of Roeselare.

Figure 3.1.2 - Current heat demand and 2050 objective in the Municipality of Roeselare.

Figure 3.1.3 - Current energy demand for mobility and 2050 objectives in the Municipality of Roeselare.

Figure 3.1.4 - Energy transition timeline in Roeselare.

Figure 3.1.5 - Energy transition strategy and renewable energy plan in Roeselare - plan view.

Figure 3.1.6 - Energy transition strategy and renewable energy plan in Roeselare - section view.

Figure 3.2.1 - Ideograms of the main solutions emerged from the participative design process in Roeselare.

Figure 3.2.2 - Schematic plan of the urban transformation concept of Roeselare.

Figure 4.1 - Visualisation of the current GHG emission of the Municipality of Roeselare in terms of virtual forestland

Figure 4.2 - Visualisation of the sequence of GHG emission mitigation measures by forestland crunching.

Figure 4.3 - Street views of 2050 neighbourhoods in Roeselare for prompting energy transition. 


\section{TABLE CAPTIONS}

$4 \quad$ Table 2.1.1 - Energy demand per sector in the Municipality of Roeselare and Emission Factors per source and fuel mix.

5 Data sources: West-Vlaanderen Province 2015; Febeg 2015. Emission Factors: IPCC 2006; Pulselli et al. 2018a

7 Table 2.1.2 - GHG emissions of the Municipality of Roeselare per activity sector. Data sources: West-Vlaanderen

8 Province 2015; Febeg 2015.

9

10 Table 2.1.3 - GHG emissions of the typical household in Roeselare per emission source.

11

12 Table 3.3.1 - Sequence of selected GHG emission mitigation measures for the Municipality of Roeselare towards the 132050 objective of carbon neutrality.

14

15 
<TABLE 2.1.1>

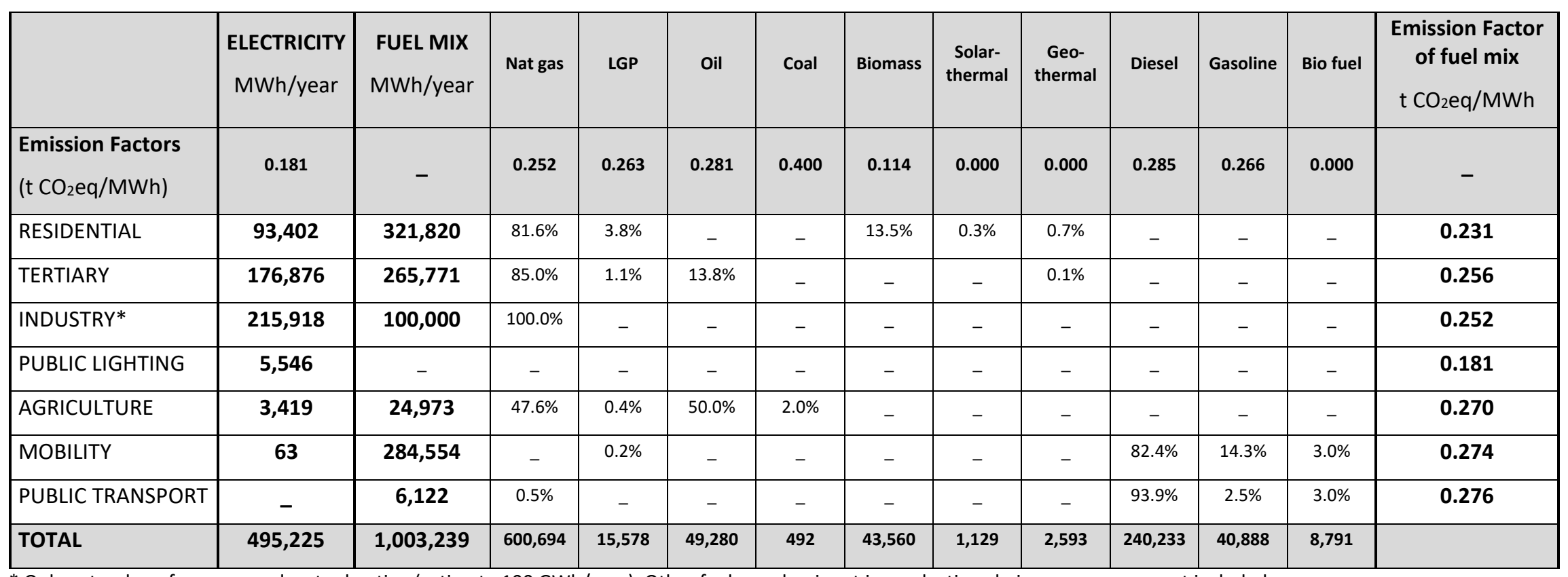

* Only natural gas for space and water heating (estimate $100 \mathrm{GWh} /$ year). Other fuels used as input in production chain processes are not included. 
<TABLE 2.1.2>

\begin{tabular}{|c|c|c|c|c|c|c|}
\hline Emission source & unit & rawdata & $\mathrm{t} \mathrm{CO}_{2}$-eq/unit & t CO 2 -eq/year & $\%$ & Note \\
\hline ELECTRICITY & MWh/year & 489,679 & 0.181 & 88,429 & $25.1 \%$ & Electricity: total multi-sectorial demand \\
\hline HOUSING & MWh/year & 321,820 & 0.231 & 74,251 & $21.1 \%$ & Fuel mix: space \& water heating and cooking \\
\hline TERTIARY & MWh/year & 265,771 & 0.256 & 67,957 & $19.3 \%$ & Fuel mix: private and public service buildings \\
\hline INDUSTRY & MWh/year & 100,000 & 0.252 & 25,169 & $7.2 \%$ & Nat. gas for heating. Production processes not included \\
\hline PUBLIC LIGHTING & MWh/year & 5,546 & 0.181 & 1,002 & $0.3 \%$ & Electricity: specific use for public lights \\
\hline AGRICULTURE & MWh/year & 24,973 & 0.270 & 6,729 & $1.9 \%$ & Fuel mix: machinery and management in farms \\
\hline MOBILITY & MWh/year & 284,554 & 0.274 & 77,881 & $22.1 \%$ & Fuel mix: private car use \\
\hline PUBLIC TRANSPORT & MWh/year & 6,122 & 0.276 & 1,689 & $0.5 \%$ & Fuel mix: public transport \\
\hline WASTE MANAGEMENT & t/year & 28,345 & 0.256 & 7,260 & $2.1 \%$ & Mass: domestic waste by households \\
\hline WATER MANAGEMENT & $\mathrm{m}^{3} /$ year & $2,521,692$ & 0.0006 & 1,476 & $0.4 \%$ & Mass: water use in households \\
\hline TOTAL & & & & 351,842 & $100 \%$ & \\
\hline
\end{tabular}

<TABLE 2.1.3>

\begin{tabular}{|c|c|c|c|c|c|c|}
\hline Household emission source & unit & rawdata & $\begin{array}{l}\mathrm{kg} \mathrm{CO}_{2-} \\
\text { eq/unit }\end{array}$ & kg CO 2 -eq/year & $\%$ & \\
\hline ELECTRICITY & kWh/year & 3,545 & 0.181 & 640 & $9.5 \%$ & Lighting \& appliances, cooling \\
\hline HEAT & kWh/year & 12,214 & 0.231 & 2,818 & $41.8 \%$ & Space \& water heating, cooking \\
\hline MOBILITY & kWh/year & 10,802 & 0.274 & 2,956 & $43.8 \%$ & Private car use \\
\hline WASTE & $\mathrm{kg} /$ year & 1,076 & 0.256 & 276 & $4.1 \%$ & Domestic waste production and management \\
\hline WATER & $\mathrm{m}^{3} /$ year & 96 & 0.583 & 56 & $0.8 \%$ & Tap water use \\
\hline TOTAL & & & & 6,746 & $100 \%$ & \\
\hline
\end{tabular}


<TABLE 3.3.1>

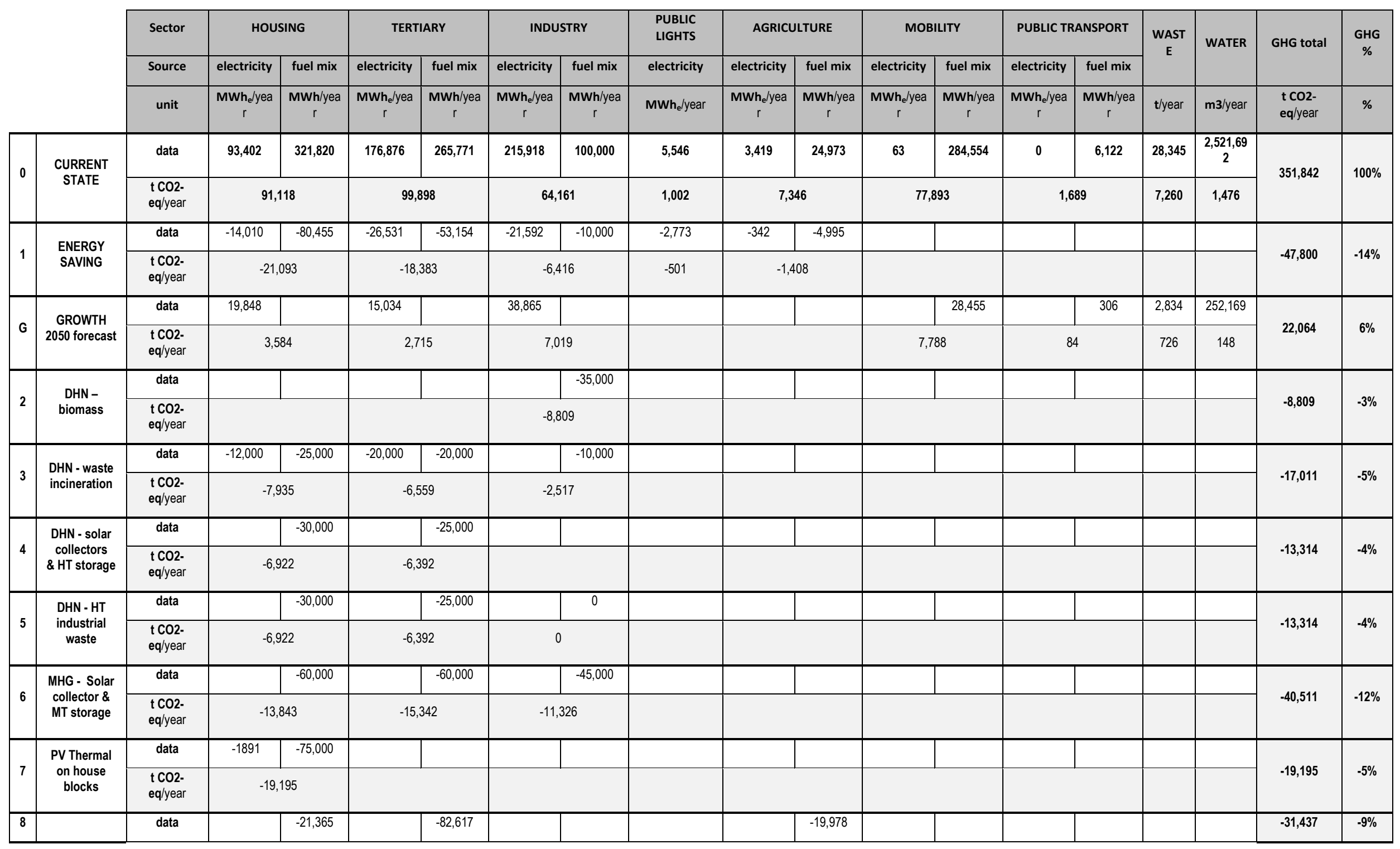




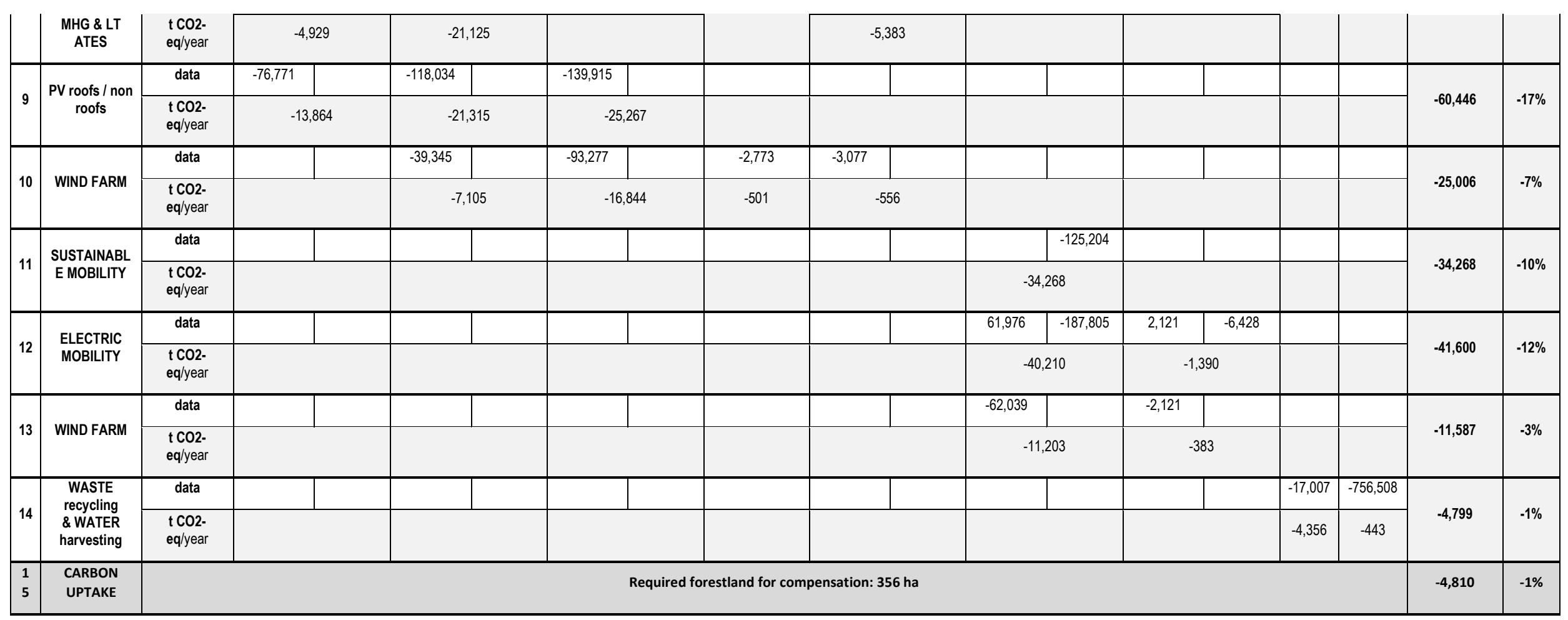

